\title{
Correction to: New Engineered Fusion Peptide with Dual Functionality: Antibacterial and Strong Binding to Hydroxyapatite
}

\author{
Razazpour Fateme $^{1} \cdot$ Gashtasbi Fatemeh $^{2} \cdot$ Shahabi Sima $^{1,3} \cdot$ Alireza Moshaverinia $^{4} \cdot$ Sadegh Hasannia ${ }^{2,5}$
}

Published online: 27 January 2020

(c) Springer Nature B.V. 2020

\section{Correction to: \\ International Journal of Peptide Research and \\ Therapeutics \\ https://doi.org/10.1007/s10989-019-09963-8}

The original version of this article unfortunately contained an error in author group. The given name and family name was swapped erroneously for co-author.

The correct name is Alireza Moshaverinia instead it was published incorrectly as Moshaverinia Alireza.

The original article has been corrected.

Publisher's Note Springer Nature remains neutral with regard to jurisdictional claims in published maps and institutional affiliations.

The original article can be found online at https://doi.org/10.1007/ s10989-019-09963-8.

Sadegh Hasannia

hasannia@modares.ac.ir

1 Department of Dental Biomaterials, School of Dentistry/ Research Center for Science and Technology in Medicine, Tehran University of Medical Sciences, Tehran, Iran

2 Novateb Research Laboratory, Dental Equipment and Bio-Material Technology Incubation Center, Tehran, Iran

3 Dental Research Center, Dentistry Research Institute, Tehran University of Medical Sciences, Tehran, Iran

4 Division of Advanced Prosthodontics, Weintraub Center for Reconstructive Biotechnology and Division of Advanced Prosthodontics, School of Dentistry, University of California Los Angeles, Los Angeles, CA, USA

5 Department of Biochemistry, Faculty of Biological Sciences, Tarbiat Modares University, Tehran, Iran 